The last days of Edmund Parkes proved the truthfulness of his life. In the very sight of death be displayed the same forgetfulness of self, the sume thoughtfulness for others, the same desire to urge forward true work, that had characterised him from boybood onward. When he believed himself to be dying and beard that I was coming to see him, he was most anxious that I should arrive before his end. The motive that prompted this anxiety was that be might with his last breath promote good and useful workit was that he might "xpress to me his earnest wish that I should exert the influence which he hoped my position might give me to stay the hands of those who, through ignorance of the value of the Army Medical School, might possibly hereafter curtail its usefulness, or even destroy it. He most earnestly impressed upon me his sense of the worth of all his colleagues, of the value of the work they were doing, and the fitness of each for his special duties. A body of men so able and so well fitted for their duties, if once dispersed, could, he said, never be again collected. In the very act of dying, then, this noble man thought most of others, and how he might best promote the progress of good and useful work when his own hand must be powerless and his own tongue silent.

While Parkes was near to us we saw how perfect was each portion of his life; but it is only when death bas placed him at a distance that we can realise how completely he stands out from his fellows. It is only now when death has placed him at a distance that we can see his character as a whole, that we can fully appreciate the harmonious beauty of the several parts of his being, and the full height of his intellectual and moral stature.

And now, Sir, that I have fiuished the task the judgment of others and my own sense of duty imposed on me, I must say that, although I have striven my best to draw Edmund Parkes truthfully, I feel, to use his own eloquent words, written for a like occasion, "how pale and tame a portrait I have drawn of this noble and large-hearted man. Would that to some pen, which could draw the outline more boldly, and could fill in the lights and shadows more delicately, this task had been assigned."

\section{Climital affectures}

\section{OSTEO-MYELITIS AND ACUTE PERIOSTITIS.}

\author{
Bx C. MACNAMARA, F.C.U.,
} SURGEON TO THE WESTMINSTER HOSPITAL.

\section{LECTURE II.}

BEFORE discussing the pathology of osteo-myelitis, I wish to draw your attention to some specimens of healthy bone. The extremities of the long bones are surrounded by a thin layer of compact osseous tissue, but the bulk of the spongy portion of these bones is constructed of a number of osseous traveculø, and the spaces between these processes are, in the living bone, filled up with soft structures (medulla), which play the most important part in the various forms of disease we shall have to consider. With the aid of preparations made by soaking sections of injected bones in solutions of chloride of gold and glycerine, I shall be able to explain to you the anatomy of the soft material filling the spaces in the spongy portions of the long bones. And let me here remark that these sof tissues are continuous with those occupying the medullary canal, and they also abut on the attached surface of the articular cartilages, actually filling more space in the spongy portion of bones than the osseous trabeculæ. The greater number of the vessels which pass into the extremities of the long bones are derived from vessels perforating the periosteum and outer thin layer of bone, and not from the nutrient artery. For instance, the vessels of the lower end of this femur have been injected from the popliteal artery, and this anatomical arrangement of the vessels will in some measure explain the fact, that in certain cases well-applied and continuous pressure round the lower end of the femur may influence inflammatory changes going on in the bone, the blood-supply to its spongy tissue being thus materially affected-in fact, a layer of extract of belladonna and mercurial ointment smenred thickly over the skin covering the condyles of the femur and knee-joint, the whole being encased in well-applied strapping, would place the inflamed intra-osseous structures in wuch the same condition with reference to their supply of blood, as the iris would be in after the pupil had been fully dilated with atropine for the cure of iritis; the supply of bluod to the bone would be restricted, and the part kept at rest-two important elements in the successful treatment of inflammation.

If we examine the soft structure in the cancellated tissue, we shall discover that it is fairly supplied with blood, many of the smaller vessels coursing along the walls of the trabeculæ, while others stretch across the intra-trabecular spaces. In addition to these vessels, the spaces contain a network of fine adenoid or connective tissue, its meshes being filled in with fatty material and a vast number of granular cells, which, as a rule, seem to adhere to or grow from the connective-tissue filres. This latter structure is not only spread throughout the spaces in the spongy portions of the long bones, but it also lines the osseous trabeculæ, and is continuous with processes of connective tissue passing through the outer lamina of bone from the periisteum. Many authorities hold that this plexus of adenoid tissue is to be considered as the commencement of the lymphatic tissue in bones. It seems to me that in the inedullary canal the evidence in favour of this view is very strong, and I think we may yet demonstrate the existence of 1 gmphatic structures in this situation. But however this may be, we certainly find that the Haversian canals contain a network of adenoid tissue in addition to their vescels, and that this connective tissue, together with its cells, plays an important part in inflımatory and other abnormal processes going on in the interior of the long bones. It is almost unnecessary for me to remark that a considerable number of our patients suffering from disease of the bone are young persons, and in these cases we shall find, in addition to the elements $I$ have already described as occurring in the cancellated tissues, a number of giant cells (nyeloid), such as we always meet with in the medullary spaces before the adult period of life.

If wo examine these sections of the articular surface of the tibia which have been rendered transparent by glycerine, we shall be able to comprehend the anatomy of the cancellated structures immediately beneath the articn'a. vartilages. The soft material filling these spaces projects down to within a very short distance of the attached surface of the cartilage, the medulla terminating in bulb-like mass \pm 8 , from which processes run along rassages in the bon: up to the cartilage. So numerous are tuese channels passing from the medullary spaces to the cartilage that the lay $r$ of compact bone they perforate may be said to be ridiled with tortuous channels, and this layer would therefore be a weak point in the bone were it not for a peculiar arrangement of its calcareous elements. With a half-inch magnifying power we can see small lumps and a quantity of grauular earthy matter dispersed in an abundant but irregular manuer in the osseous lamina between the cartilage and the cancellated structure, and the canals I have described pass up towards the cartilage through this calcareous layer, which, from its peculiar construction, is apt to resist inflammatory or other abnormal action going on in the part; at the same time changes occurring in the medullary sub. stance can pass along the contents of the canals to the attached surface of the cartilage.

We may now proceed to examine the alterations which have taken place in a portion of bone affected by inflammation, and we can hardly have a better illustration of what occurs under these circumstances, than that afforded us by sections made through the inflamed spot in the lower surface of the astrayalus, which I showed you in the last lecture in the case of $W . S-$, reported very accurately for me by my dresser, Mr. Trewman.* As a consequence of the increased action going on in this inflamed patch of bone, which is in immediate proximity to the cartilage, we find

* The Kanger, zol, i, 1876, po 805 . 
that rapid proliferation has taken place in the nuclei of the neighbouring cartilage cells, each nucleus dividing into four, six, or eight parts; but, in addition to this, you mas notice that a great number of the original cartilage cells appear to be, as it were, in a pit, as seen by transmitted light. This appearance is due to an increase in the contents of the cavity, within which the cartilage-cells lie; and, on examining this specimen with a high magnifying power, we shall discover that the abnormal contents of these cartilage cavities are due to a granular material (protoplasm) which we can clearly trace from one or more of the canals leading from the medullary spaces down to the cartilage. This medullary matter, having rapidly grown in consequence of the hyperaction going on in the bone, has infiltrated the cartilage, and, passing into the cavities of its cells, has there continued to grow; so that many of these cartilage cavities have become large irregular spaces, and, these uniting with one another, a hole has been formed in the cartilage, which, had it increased in size, would have opened on the free surface of the cartilage, and thus formed what we commonly designate an ulcer. In this specimen, therefore, we have clear evidence as to the fact that osteitis (or, as I prefer to call it, osteo-myelitis) may lead to the ulceration of the articular cartilages, and that, the cartilage having been perforated in this way, a sinus passes through it leading into the medullary spaces in the spongy portion of the affected bone, from which the protoplasm which bas caused all the mischief has in the first instance advanced.

With reference to the bone, the most obvious pathological alteration we notice in the specimen now under our observation, as the result of the inflammatory process, is that its vessels are engorged with blood, and that the parts surrounding them are stained by the colouring matter of the red corpuscles; it is not simply serum and white globules that have passed from the vessels into the neigh. bouring tissues, but that there has been a disintegration of red corpuseles, and their contents bave percolated the in. flamed area. Beyond this we observe that the fatty matter contained in the medullary spaces is diminished in quantity, and that the giant cells are greatly increased in number, almost entirely occupying the whole of many of the medullary spaces; and doubtless, unless the inflammatory process were excessive in its action, it is from these cells that new bone would have been produced, the layer of newly-formed osseous tissue acting as a protective influence against the absorption of the products of inflammation into the system, in the same way as the walls of an abscess preserve the circulating fluid from the passage of pus into the blood. We shall subsequently see how beautifully this action on the part of the cells has worked in the case of chronic osteo-myelitis I referred to in my last lecture, but in the instance now under consideration, the disease being acute, the myeloid cells have exceedingly multiplied in con sequence of the over-action going on in the part. But they have not had fair play; surrounding circumstances have choked their growth, and here we see them crowding and pressing on one another, striving, as it were, to escape from their confinement in the medullary spaces. With a light brush we may sweep away these giant cells, and then we shall notice more clearly that the cells of adenoid tissue in the cancellated structure are infinitely more numerous than in health. The giant cells, in fact, lie imbedded in a fibrous material which is crowded with granular cells; these may be derived from the blood, but I am disposed to believe they are the offspring of the original cells I described to you as existing in the connective-tissue fibres in this locality, and we have evidence in cases of necrosis that these cells may either degenerate into pus, or they may become developed into granulation-tissue. In addition to these cells the medullary spaces contain a large quantity of granular protoplasm, some of which, as we have already observed, has passed into the neighbouring cartilage, and much of it has evidently been absorbed through the canaliculi, and so entered the lacunæ of the surrounding osseous trabeculæ I am aware that it is a disputed point as to the part which the bone-cells of the lacunæ take in the process of osteitis, and it is not my province to pass an opinion on the conflicting views held on this subject, but simply to help you to interpret the pathological changes that have occurred in the specimens now under our consideration. From these you will see that many of the canaliculi leading from the inflamed medullary spaces to the lacunæ are evidently en- larged, and most of the lacuna are even four times their natural size, being filled up with granular matter; in fact, they are in much the same condition as the cartilage-cells, having been invaded by a quantity of rapidly-growing protoplasm from the medulla. 'T'he normal function of the living matter (nucleus) contained in the bone-corpusole is impaired, and you must hen $r$ in mind the fact that the osseous structure immediately round one of these corpuscles is, as Dr. Beale says, furmed material, being in bealth repaired and kept in its normal state through the action of the living protoplasm in the bone-cell. Destroy this nucleus, and, the nutrition of the surrounding area of hard bove, depending on it, being no longer accomplished, a cavity is formed round the bone-corpuscle, which in the case we are now considering is occupied by the growing protoplasm from the medullary spaces. Under the influence of the inflammatory process one lacuna after another becomes destroyed, the spaces they occupied run into one another, and a cavity occurs in the trabecula, which ultimately opens directly into the nearest medullary space. The form this cavity takes is that of the original growth of the lacuna system, being thus more or less circular in figure. It is evident, therefore, that the osseous framework of bone plays but a very small part in cases of osteo-myelitis, and, in fact, we may have almost the whole of the sof $t$ structures contained in one of the long bones absolutely destroyed and the patient killed from the effects of septic poisoning; and yet we might examine sections of the dry bone under the microscope, and be unable to discover that the Haversian system had been in any way implicated, illustrating the point I have so often dwelt upon, that the study of pathology is apt to mislead us unless we examine specimens of the structure implicated immediately after death, and alter their condition as little as possible by chemical reagents. It may be that the original cartilage and bone-cells take a more active or even a suicidal part in the disintegration of struc. tures depending upon them, but we fail to see any indication of this process in the specimens now before us. You are aware that many authorities believe the disintegration of the bone in cases of this kind is due to the formation or secretion of an acid fluid in the inflamed structures, which is supposed to dissolve out the earthy particles from the bone, destroying it by means of chemical action. I can only say that my observations have faled to convince me that any such acid is formed. If such were the case, surely the matter would have been set at rest by chemists long ago. Nor do we require the belp of a theory of this kind to explain the phenomena I have described, for if the nucleus or living portion of the cell is destroyed, evidently, the parts around which depend upon it being no longer repaired, a cavity must result in the osseous structure, such as $\mathrm{I}$ have above noticed. In ordinary language, if the source from which a stream has been fed becomes dried up, we hardly talk about the river having become absorbed; and so in the matter of the cartilage and bone-cells, if the living material from which the parts are produced ceases to be, evidently an empty space occurs around the site of the original protoplasm, which cavity, as in the instance now under considera. tion, may speedily be filled up by extraneous matter.

As the inflammatory process advances in the medullary cavities of bone, pus and the disintegrated surrounding materials become mixed together in a decomposing mass. Septic matter of this kind, although no external air is admitted into it, is a deadly poison if introduced into the circulation; for, as I told you the other day, I have seen death resulting from a large plug formed in the right side of the heart, and extending into the pulmonary artery; from the absorption of matter of this description from an injured spot in the diploe of the skull. This tendency to septic poisoning is enhanced when air gains access to the products of the inflamed bone, as is usually the case in usteo-myelitis, and in acute cases there is no chance of a limiting membrane being formed round the inflamed part, and heuce the blood-poisoning that so frequently occurs in this form of disease. It is not very uncommon subsequent to amputation for our patient to die suddenly some eight or ten days after the operation, and if we seek for the cau e of death, we may find in the right side of the heart a firm clot of fibrine which has killed the patient; and if we examine fresh sections of the bone cut through during the operation, we may often discover in such cases that the contents of the medullary canal is already largely made up of putrid 
material, which, having been absorbed into the blood, has destroyed the patient as above described.

In acute periostitis the condition of the inflamed parts is very different from that found in osteo-myelitis, as the section of the fibula referred to in my last lecture demonstrates. In this instance, although suppuration bas occurred between the bone and the periosteum, and the sbaft of the fibula been thus laid bare, still the soft structures outside the periosteum have also been inflamed; in fact, an abscess has formed round the bone, and the inflamed area is thus limited by consolidated tissues, through which the absorption of the products of the inflamed tissues into the system is greatly hindered. It is true so grave a lesion to the periosteum as that above alluded to must affect the nutrition of the bone, but, unless the contents of the medullary canal participate in the inflammatory action, the patient's life is not likely to be endangered from pyrmia. In the case before us the contents of the medullary canal and Haversian system surrounding it seem to be perfectly healthy, their vascular supply being derived from the nutrient artery of the bone; but in the outer layers of the fibula, which have grown from and been nourished by vessels from the periosteum, we find that a number of cavities have been formed through the breaking down of lacunx in the manner I have described, and the layers of bone surrounding the shaft of the fibula were becoming necrosed in this way. It is easy, however, to imagine that in acute periostitis the inflammatory action might be propagated along the connective tissue surrounding the nutrient artery or the vessels passing into the cancellated tissue, and set up a similar action in the medullary structure, which in it turn would very probably induce psæmia; but then the disease is no longer one of periostitis, but of osteomyelitis.

From a practical point of view we may conclude that in acute periostitis, although the fever runs high and the parts affected are intensely inflamed, still we may fairly hope, by very free incisions down to the bone, to arrest the dange of septic poisoning; and if the disease has occurred to parts below the knee-or elbow-joint we may save the limb. The case is much more serious if the humerus or femur is at tacked by acute and rapidly spreading periostitis; for the surrounding tissues become extensively implicated, the vessels may be eaten into, and the loss of blood and profuse drain of matter from the part render amputation at the shoulder- or hip-joint nesessary, and I need hardly add that these are operations from which we justly shrink under the circumstances. If, on the other hand, during an attack of this kind, pyæmia supervenes, we may be almost certain that the medullary tissues are implicated; and, in $\mathrm{my}$ opinion, wherever the seat of the disease may be, the sooner the part is removed at or above the joint beyond the disease the greater will be the chances of the patient's recovery; every day, I may say, almost every hour, you delay this proceeding renders the prognosis more unfavourable.

\section{NOTES ON UTERINE PATHOLOGY.}

\section{By GRAILY HEWITT, M.D., F.R.C.P.}

\section{II.-DESCRIPTION OF THE VARIOUS ABNOR MAL CONDITIONS} OF THE UTERINE TISSUES. (CoNTINURD.)

For the sake of distinctness $I$ have in the foregoing remarks on the various abnormal conditions of uterine tissues cunsidered only the nulliparous uterus. It will be necessary now to consider the various physical changes met with in the uterus when pregnancy has occurred.

(A) Softness. After the pregnant uterus has expelled its contents at full term, it is soft, as well as of considerable size; and when an abortion has occurred the condition is the same, though the size is less. Normally, the process of "involution" reduces both the softness and the size, in accordance with laws now well known. But when the normal involution is disturbed the uterus may be found very soft a considerable time after it has been emptied of its contents. This unduly prolonged softness indicates generally weakness, slow circulation, feebleness of consti- tution, and slowness of nutrition. The patient slowly recovers her strength, but if well fed, and not allowed to move too soon, the uterus undergoes a change from softness to firmness, and becomes reduced in size. But the uterns may be found still very unduly soft a montb, six wetks, twis months, or even longer after labour.

This defective involution, associated, as it generally $i$, with the sof tness of the tissues, renders the organ very liable to undergo change in shape.

Imperfect contraction during the period immediately following the third stage of labour is accompanied with considerable softness of the organ. This is, it may be said, only a part of defective involution, but it deserves separate mention. And, as is well known, the uterus frequently contracts perfectly at first, but the contraction fails a little later, and it becomes again very soft.

Pregnancy, then, plays a very important part in conferring upon the uterus a physical quality which, if persistent (defective incolution), predisposes it to various disturbances. The condition of the soft, imperfectlycontracted uterus after delivery is in some respects like that of the uterus, soft and weak from imperfect nourishment, as sometimes ohserved in young women who bave never been pregnant. The difference is one of degree, the uterus being, of course, wuch smaller in the latter than in the former case. And inasmuch as the soft, recently. impregnated uterus is large, bulky, and heavier than usual, it is more easily affected by the action of forces calculated to alter its shape and derange its position. In otber words, the uterus which has recently undergone pregnancy is more liable than the nulliparous uterus to become affected with those disorders to which undue sof:ness constitutes a predisposition.

Very many cases of cbronic flexion of the uterus are distinctly traceable to slight accidents, or even ordinary exertion, acting on an organ soft and unduly pliable during the first two or three weeks following parturition. And in some cases the history distioctly shows that the malady originated within the two or three days following the labour.

Abortions are doubly interesting considered from this point of view. The abortion is frequently caused by dis. tortion of shape, and sometimes the distortion in shap occurs suddenly, and calises the abortion. But it is certainly the fact that the abortion frequently very much intensifies an existing flexion. After the expulsion of the ovum the organ is soft, large, and pliable, and in its flaccid. empty state the uterus becomes frequently even more bent than it was before. Thus the evil may be perpetuated.

The uterus baving thoronghly recovered from the effects of pregnancy, may of course, as is the case with the nulliparous uterus, become subsequently affected with softness from otber causes.

(B) Hardness. An enlarged indurated uterus is common in chronic uterine disease where the patient has beev pregnant. The hardness is accompanied with considerable enlargement in many cases. The whole cervix may be unwieldy, distorted, its lips everted, and a profuse secretion escaping from its interior. The body of the uterus is frequently in a like condition-bard, enlarged, and heavy. The uterus as a whole is hypertrophied in many instances. These are cases for the most part in which the uterus has primarily failed to contract efficiently after labour; bas secondarily become affected with change of shape; and, in the third place, has become the seat of those chronic hypertrophic nutrition changes which were formerly spoken of as chronic inflammation, but for which some such designation as "areolar hyperplasia" is more appropriate. 'The mechanism of the process by which these results are reached is in no wise different in kind from that which is observed in the nulliparous uterus, but it differs in regard to its results for the bulk of the affected parts is much greater when the disorder follows pregnancy or abortion than under ot bex circumstances. It is not uncommon, for instance, to find the uterus three times its normal size a year or two after the termination of a particular pregnancy, the cervix large, hard, hypertrophied, and altogether abnormal in shape, concurrently with which the organ is the seat of very decided flexion; and an examination proves that the body of the uterus is equally enlarged, hard, and indurated. There are necessarily great variations in different cases, for the hardness is sometimes exchanged temporarily for softness; further congestions occur from time to time, producing 